\title{
Key Performance Indicators for program scale-up and divergent practice styles: a study from NSW, Australia
}

Grøn, Sisse; Loblay, Victoria; Conte, Kathleen P.; Green, Amanda; Innes-Hughes, Christine; Milat, Andrew; Mitchell, Jo; Persson, Lina; Thackway, Sarah; Williams, Mandy

Total number of authors:

11

Published in:

Health Promotion International

Link to article, DOI:

10.1093/heapro/daaa001

Publication date:

2020

Document Version

Peer reviewed version

Link back to DTU Orbit

Citation (APA):

Grøn, S., Loblay, V., Conte, K. P., Green, A., Innes-Hughes, C., Milat, A., Mitchell, J., Persson, L., Thackway, S., Williams, M., \& Hawe, P. (2020). Key Performance Indicators for program scale-up and divergent practice styles: a study from NSW, Australia. Health Promotion International, 35(6), 1415-1426.

https://doi.org/10.1093/heapro/daaa001

\section{General rights}

Copyright and moral rights for the publications made accessible in the public portal are retained by the authors and/or other copyright owners and it is a condition of accessing publications that users recognise and abide by the legal requirements associated with these rights.

- Users may download and print one copy of any publication from the public portal for the purpose of private study or research.

- You may not further distribute the material or use it for any profit-making activity or commercial gain

- You may freely distribute the URL identifying the publication in the public portal 


\title{
KPIS IN HEALTH PROMOTION AND DIFFERENT PROGRAM IMPLEMENTATION PRACTICE STYLES, A STUDY FROM NSW, AUSTRALIA
}

Sisse Grøn, Victoria Loblay, Kathleen Conte, Amanda Green, Christine Innes-Hughes, Andrew Milat, Jo Mitchell, Lina Persson, Sarah Thackway, Mandy Williams and Penelope Hawe

*Corresponding author: Sisse Grøn: smfg@live.dk

\begin{abstract}
Implementing programs at scale has become a vital part of the government response to the continuing childhood obesity epidemic. We are studying the largest ever scale-up of school and child care obesity prevention programs in Australia. Health promotion teams support primary schools and early childhood services in their area to achieve a number of specified, evidence-based practices aimed at organisational changes to improve healthy eating and physical activity. Key performance indicators (KPIs) were devised to track program uptake across different areas - measuring both the proportion of schools and early childhood services reached and the proportion of practices achieved in each setting (i.e., the proportion of sites implementing programs as planned). Using a "tight-loose-tight" model, all local health districts receive funding and are held accountable to reaching KPI implementation targets. However, local teams have independent discretion over how to best use funds to reach targets. Based on 12 months of ethnographic fieldwork and interviews across all districts, this study examines variations in the decisionmaking and strategising processes of the health promotion teams. We identified three distinct styles of practice: KPI-driven practice (strategic, focussed on targets); relationships-driven practice (focussed on long term goals) and equity-driven practice (directing resources to sites most in need). In adapting to KPIs, teams make trade-offs and choices. Some teams struggled to balance a moral imperative to attend to equity issues, with a practical need to meet implementation targets. We discuss how models of program scale-up and tracking could possibly evolve to recognise this complexity.
\end{abstract}

\section{INTRODUCTION}

As rates of obesity and chronic disease continue to cause concern (AIHW, 2014), unprecedented resources and opportunities for prevention have been generated in Australia. The National Partnership 
Agreement on Preventative Health between the Commonwealth Government and the States was launched in 2008 (Council of Australian Governments). In response, the state of New South Wales (NSW) developed the largest ever effort to prevent obesity in schools and early childhood service settings in line with the World Health Organisations recommendations of multi-strategy approaches (The commission on ending childhood obesity (2016). Two flagship programs of the Healthy Children Initiative (HCI) were created as part of a fleet of wider strategies across the state: Live Life Well at School (LLW@S) and Munch \& Move.These programs aim to improve primary school and early childhood education and care service environments by supporting healthy eating and physical activity (Hardy et al, 2010; Wiggers et al, 2013; Innes-Hughes et al 2019). The evidence-base and implementation learnings on which these programs were designed were established, in part, by a previously implemented at-scale suite of childhood obesity interventions that demonstrated a $1 \%$ per year reduction in childhood obesity, against an otherwise increasing prevalence (Hardy et al, 2010; Wiggers et al 2013). According to program monitoring data, $89 \%$ of all early childhood services and $83 \%$ of all primary schools in NSW are currently participating. Elsewhere, similar approaches to modifying school environments (in terms of the types of food available and the time spent in the school day on physical activity) have shown encouraging reductions in childhood obesity (Fu et al 2018).

The HCI began in 2011 (Innes-Hughes et al 2017). By 2012 it included targets for the proportion of schools and child care services which implemented the required policies and practices or Key Performance Indicators (KPIs). The KPIs also formed part of the service agreements (funding agreements) between the Ministry of Health and local health districts. In 2014 an electronic monitoring system, the Population Health Information Management System (PHIMS) was introduced with the aim of helping local practitioners track the delivery of the HCI and the consequent adoptions of new health promoting practices in schools and early childhood services in their remit (i.e., the KPI achievement). While KPIs are routinely used in the clinical and the service provision area in NSW (NSW Ministry of Health, 2017a; NSW Ministry of Health, 2017b), their large-scale introduction into disease prevention and health promotion has been relatively new.

KPIs are the central concept of what has been called "New Public Management," a movement which emerged during the 1980s and 1990s as a form of governance that purported to ease the administrative burden (at the central level) and allow work force units to be more self-directed (Evetts, 2009). New Public Management is rooted in a business model which posits that administrative bodies may perform better if they are thought of as competitors delivering services - ideally with more local decision power, but also emphasizing efficiency and cost reduction (Evetts, 2009). The model uses performance targets and performance evaluations as the means to hold a self-directed workforce, or entity, accountable. KPIs 
are components of performance monitoring systems which are usually comprised of (1) an activity or set of activities, (2) some form of measurement, (3) data, (4) the application of some set of criteria to the data; and (5) some use of the data (Pollitt, 2013).

Performance management systems, and New Public Management, have been critiqued (Shore and Wright 2015) in both the private and public sectors where 'audit cultures' and 'governance by numbers' have a range of effects (Power, 1999; Evetts, 2009; Strathern, 2000). In her ethnographic study of quantification and 'indicator culture', Merry argues that when it comes to KPIs, the point is not whether they are "inherently" good or bad. Rather, the significance of KPIs is that they contribute to the ways in which the world, and the practice of work, is understood (Merry 2016, p33). Discussions of accountability have recognised a 'pull' in two different directions - organisational and professional (Evetts 2009, Kouzes and Mico 1979). There may also be multiple, co-existing and competing "logics" or sets of assumptions about how people think and what motivates them. In teaching the practice of medicine, for example, two "logics" have been observed to co-exist - "science" and "care" (Dunn and Jones, 2010). It is thought that problems with performance management can arise if performance management systems ostensibly cater too much to one logic at the perceived expense of another (Pollitt, 2013).

In NSW, the delivery of the HCI and the associated e-monitoring system is based on the principle of usercentred design (Bødker, 2000) and sets out to be consistent with a "tight-loose-tight" approach to policy and program implementation (Dickens, 2016). That is, the parties are to be tight (specific) about the problem and goal, loose (flexible) about how to reach the goal, and tight (specific) about the target to be achieved (Dickens, 2016). This approach is largely in keeping with understanding health care delivery settings as complex adaptive systems (Plesk and Wilson, 2001). However, it is not - strictly speaking consistent with the traditional public administration and performance management systems and use of KPIs as originally conceived in the 1990s. Back then so called "top-down approaches" were those led by policy makers. These approaches identified best practice through research and then devised ways to diffuse, facilitate and incentivise the faithful delivery of best practice programs by practitioners (Flay, 1986). By contrast, "bottom-up approaches" assume that the best approaches to achieving health gains can be discovered through the cyclical learning methods of practice (as represented in models like the 'plan-do-study-act" cycles (Varkey et al, 2007; Miller and Shinn, 2005; Conte and Hawe, 2018). Scholars have documented inevitable tension between top-down and bottom-up approaches.

Others have recognised the benefit of this perennial tension (Hubbard \& Ottoson, 1997). The contest forces both management and practice values to be constantly and consciously articulated (Hubbard \& Ottoson, 1997). This then potentially enables spaces for creating better dialogue, understanding and ownership, and reinforcement of those actions that will lead to stronger and sustained program benefits. 
Indeed, with this way of thinking, implementation is a process of mutal adaptation between the program and the context (Hubbard \& Ottoson, 1997). In simple terms, the idealised model of program diffusion and delivery was (and in many ways still is) "tight-tight-tight". But these days there is more acceptance and interest in "tight-loose-tight," . However, there are not enough insights and understanding about what "loose" actually means, including both its pitfalls and benefits.

In this paper we set out to explore different approaches to the practice of health promotion within the context of a childhood obesity prevention program state-wide scale-up focussed on KPI achievement for implementation. By using ethnography, our focus of attention is on the everyday decisions, actions and conversation of practitioners within a system of KPI use and monitoring. We are not concerned here with whether the uptake of the programs reduces obesity. Rather, our interest was in the everyday dynamic of action and decision making within the presence of a KPI based- system designed to increase program diffusion across the state. We also acknowledge that the demand for accountability in scaled up evidence-based programs could have a reductionist effect - by narrowing the focus of attention of a multifaceted program.. On the other hand, the programs exist in a political context with a demand for measurable accountability. As a research partnership between policymakers and an ethnographic research team, we are studying this tension and trying to find new ways of enacting accountability. While the field of health promotion has had long interest in accountability, there is a long standing concern that a "tickthe-box mentality" in performance monitoring could lock practitioners into rigid behaviour patterns that preclude innovation and capacity to service wider needs (Maycock and Hall 2003). To date, to our understanding, no in-depth ethnographic investigation of the use of KPI systems in improving the scale up of chronic disease prevention programs has taken place.

\section{CONTEXT}

The state of NSW is divided into 15 Local Health Districts (LHDs) ranging in population size from 939,464 to 30,901 (Health Statistics NSW 2015). In one rural area, one team serves two LHDs. HCI is funded and supported through the NSW Ministry of Health (Innes-Hughes et al 2019). Annual health service agreements (New South Wales Ministry of Health 2016) set out service and performance expectations. Collectively, HCI teams support over 6,000 primary schools and early childcare services to achieve a specified number of evidence-based practices. The variation between LHDs is massive. Each LHD has a health promotion team ranging in size from 8 to 98 and the teams delivering the HCI programs range from 3 to 25 staff. The number of sites each HP officer support range from under 50 sites per 
practitioner to over 150 and the time they need to spend on the road to reach their site ranges from minutes in urban areas to over 3.5 hours in remote areas. The population in NSW's 15 LHDs likewise vary vastly both in numbers and in cultural and socioeconomic characteristics. A related paper reports on the differences in context across LHDs in more detail (submitted).

There are 10 KPI implementation indicators (or program practices) for LLW@S and 15 for Munch \& Move, the two programs on which we focused this study. The KPIs were developed based on best practice guidelines in early childhood services and a validation study done as part of Good for Kids (Dodds 2014; Farell et al 2014; Green et al 2018; Wiggers et al 2013).

Three illustrative KPI implementation indicators for the programs are shown in the Box below. Please see appendix 1 for the full list.

[insert Box 1 here]

The relationship between the various sections of the state health department and how they support the KPIs in practice is illustrated in Figure 1.

[insert Figure 1 here]

\section{METHODS}

The study is part of a multi-site case design, taking a mixed-methods approach to understanding the use of an electronic monitoring system (PHIMS Population Health Information Management System) to aid the roll out of two childhood obesity prevention programs. The research is guided by 7 research questions. So far the results report on the breadth and intensity going in to achieve a change in organisational practice (submitted) and the informal recording systems that have grown up to record progress and communicate across teams as they implement the program (Conte et al 2019). Please see Conte et al 2017 for a detailed description of the research protocol (Conte et al 2017). The focus of the current paper is on the everyday dynamic of action and decision making within the presence of a KPI system designed to increase program diffusion across the state. This work is being conducted within the context of a university-policymakerpractitioner research partnership as part of a prevention research centre in Australia, committed to 
knowledge co-production (Wutzke et al 2017). Three researchers conducted the "multi-sited"

ethnographic field work (Fortun, 2009; Marcus, 1995) among the 14 teams during a period of 12 months, spending 1-5 days with each team of practitioners; working alongside them in their offices, tagging along for their site visits, workshops, and meetings and engaging in conversational interviews (Spradley, 1979). The ethnographers sensitised themselves with some papers illustrating some main concepts and insights before conducting the fieldwork. These included institutional theory (e.g., Scott et al, 2000; Boxenbaum \& Jonsson 2008; DiMaggio\& Powell 1991), implementation research (e.g., May et al 2016; Bauer et al 2015) and health promotion practice (e.g., Hawe et al 1998).

During the analysis phase we have expanded our theoretical horizon with performance management and audit culture theory (Power 1999; Merry 2011; Shore \& Wright 2015; Pollitt 2013; Andersson \& Denvall 2016) as these themes emerged as important.

A grounded theory approach was used to generate a project codebook. Each field note was read line-byline with the researcher highlighting each key concept and writing a note, impression, or initial analysis about each (Hsieh \& Shannon 2005; Saldana, 2012). These initial 'codes' were reviewed, discussed, revised, consolidated and further specified to develop the project codebook over an iterative process of coding conducted by three reviewers.

Subsequently, each researcher wrote a case summary of 'their' LHDs from a template covering general areas such as team organisation and local demographic context. We then conducted a series of analysing workshops where we broke the data up and tested different typologies, this resulted in a series of tables. The tables covered the whole dataset and our full set of research questions ([Protocol paper Removed for blinding]). For this article we took as our departure point any issues relevant to KPIs and three factors emerged as central to describe the teams' practice in relation to the KPIs. For each factor we placed the teams according to the information they had given us during fieldwork, discussed the fit and reallocated until we agreed. For some teams the picture was clear, for others we diverged between factors. See Table 1. The quotes in the results section are from our fieldnotes.

A combination of informant checking (feedback sessions with participants) and researcher triangulation have been applied. In this article the names of the participants have been changed and their workplaces given pseudonyms.

\section{RESULTS}


Three types of practice styles emerged from our analysis: KPI driven, relationship driven and equityvalue driven. In the following we present some of the data that reflects the variety and similarities between the teams.

All 14 HCI teams in NSW consented to participate and the researchers were welcomed throughout the state. One team, however, was so fragmented, that it was not possible to characterise them as having a 'team' approach'. Our observations in the team are part of our data-set, but we have chosen not to include the team in our typology.

\section{For some teams, KPIs were a new concept, and their role was unclear at the start}

Some teams seem to have initially had a policy of not letting the KPIs direct their work, and it was not clear to them how the KPIs would be used by the Ministry of Health. As one explained to our researcher:

Anna explained that from the start, their directive from management had been to focus on quality, and not to let PHIMS/KPIs drive your work. ... Lexie gave the impression that it wasn't a clear communication from the Ministry as to how they were to approach the KPIs, she said that instead of someone from the Ministry just saying that they would be publishing the KPIs and rating us on this basis, it was left ambiguous...

But this situation quickly changed and the roles of KPIs became clearer after the Chief Executive in the LHD received a briefing from the state team:

But when they met about the KPIs, their Chief Executive was embarrassed that they had not been achieving what other LHDs were achieving in terms of the KPIs, and wanted to know what was going wrong in their practice.

\section{For other teams, however, the role of KPIs was clear, and the climate could be competitive}

In other teams KPI achievement was sometimes viewed as a competition, as became clear to our researcher, when she observed a team meeting:

Selda has circled where their team are saying, "we are here". "How do you know?" someone asks. "Piper looked it up", Selda tells them. "She's all about the competition." 
Accountability is taken seriously.

She explains that their performance is part of the service agreement with the $L H D$, so it is right at the top in their priorities and their director is held accountable for the results.

\section{The KPIs focus attention on particular practices}

Some LHDs identify specific indicators to target and develop a strategy for all sites to obtain these. We were also told of LHD-level strategies where each staff would take one of the lowest performing indicators and develop a strategy around addressing them. This work is often facilitated by special initiatives from the Ministry of Health, such as a grant program to support a particular indicator.

They would look at their overall KPI achievement and see if there was an KPI that could be boosted, practice \#8, 'service has a food policy' is an example where they can work across all their sites and do a mass update. For example, they would send an email to all services without a policy and say 'if you make a food policy, we will provide you with this or that piece of equipment'.

\section{And work with sites becomes highly considered and strategic}

Some teams engage in highly strategic approaches, as in this team where they are able to plan ahead a year in advance:

Each year, the whole team meets and discusses what the needs/asks of the schools are, and then they develop strategies to help them. Then, secondarily, they look at the practices and discuss how to tick them off "with minimal effort."

(With a deadline looming) she and Su-Yi will print out a list of sites and see which ones they can focus on to meet the KPIs. 
Or this team, where they described how they perform at mid-level deliberately in order to keep their resources:

Generally, they are doing well, but they are fine with there being fluctuation in how well they are performing from quarter to quarter. The change is good because it looks like they are "working hard for the money they are given." They worry that if it looks like it's too easy for them to meet KPIs, then the Ministry of Health will take money away from them, thinking they don't need it.

In one team, they found a way to work with the KPIs as their guiding tool:

Another important change is that previously, they would have spent the majority of their time and energy working with the low performing schools/struggling schools/disadvantaged schools. Now, they spend their time and energy focusing on schools that are just on the tipping point, who if they focus on, will help them to reach their targets.

Yet, as one practitioner explained, some practitioners also look for opportunities to engage in work that goes beyond the KPI requirements.

But quite often (she told me) "we want to go beyond our KPIs and put your health promotion skills into play"

\section{The validity of the KPI in the practitioner's eyes affects their approach to achieving them}

For the following practitioner, her belief that the KPIs reflect an evidence-based approach has made her persist despite being part of a team that has not taken the strategic approach to reaching KPIs:

I have been hearing a lot about the difficulties Mary has had and yet she has persisted here, so I ask what has made it worth it for her. She answers that she is passionate about children's health and the program is evidence based, it works. It is just the requirements that are a little bit out, but working with teachers, building the relationships, it is absolutely the right way to go about it. 
In one team, the manager questioned whether the information collected for KPI achievement provided sufficient evidence of real change:

Gives an example of (an indicator) aimed at involving parents - the "only (indicator) that engaged a broader school environment" - was removed from the new set of (indicators). But, this was the only (indicator) to her, that had any real meaning or any teeth to it. She says most of the (indicators) are easy to achieve, and don't really provide any indication of the real work that they're doing.

While this manager has encouraged her team to view the KPIs as secondary to their approach to practice, saying:

"if we don't make them, we don't make them, and I don't care"

By contrast another HCI team, in partnership with a local university, consciously strives to add the evidence base on how best to implement the programs by engaging in randomised controlled trials of alternate implementation types of strategies. For them, the rationale for the program is strong and they proudly engage in shaping that evidence further using traditional 'best practice' evaluation methods. We have named the team practices represented through the quotes we have presented so far, 'KPI driven practice'. But there was also a different way of engaging with KPIs present in our data.

\section{Pre-existing local relationships may be critical to how sites are steered towards KPIs}

While some teams plan their work around the KPIs, meaning that they talk about how they are going to meet each of the KPIs one at a time, other teams prefer to approach the issue of meeting KPIs on a siteby-site basis, that is, taking all the KPIs for a particular school or childcare service into consideration. In the quote below, a practitioner explains how he tries to nudge each site to adopt more practices according to how ready they are, and the character of his relationship with the site:

He feels he has a good relationship with the site we are going to, there wasn't a lot happening, but they have started some things up. He thinks they are in the stage where they have projects, but the practices are not yet embedded. 
It is characteristic of some teams to emphasize their relationships with the schools and services in their area in their conversations with (ourselves) as researchers. And often they would also make it clear that they prioritise those relationships over KPI performance, as in this conversation:

She tells me that they have always had the attitude that they are not keen on going out to schools to report on them or sort of ticking off boxes. Because if you want to get a sustainable relationship with them, you have to listen to their needs.

One person went as far as to say

"I don't care about KPI achievements... I don't seek that validation for my performance. That doesn't represent what I do. (But) for some people, PHIMS performance is their performance."

We have named the team practices represented in the quotes presented above 'relationship driven practice'. But a few teams seemed to have yet a third approach as described below

\section{Equity involves multiple additional considerations and conflicts}

PHIMS provides a facility to tabulate KPI achievement according to whether or not a site has a high Aboriginal and Torres Strait Islander or a low SES population. Teams track this and compare their achievements to the state average. Some teams try to use their resources to develop extra materials and projects to assist schools with such populations. Some teams struggle to meet their KPIs as in the following quote from a conversational interview:

I ask if the bar is the same for all LHDs, because I know that they have a large proportion of socially disadvantaged here ... and she says that they have to meet the same targets as everyone else, if there are hindering circumstances as there indeed are here, it is up to the LHD to allocate more resources for staff for the HCI programs. 
Selda explains that the practices are definitely harder to meet (with low SES schools) but whether they spend more time with (those low SES) schools is another question. ... There are some low SES that prioritise (HCI) and are doing amazingly, whereas there are others who don't have any time for the program unless you are offering a lot of money.

But low performance is not necessarily equated with low socio-economic status. In some cases it is more a case of local instability in the health promotion team, where high staff turnover makes it difficult maintain the relationships with sites that lead to KPI achievement. Also, the attitude of the teachers or director of the early childhood service can make a difference with low SES areas, with one practitioner relating a story to us about coming out to do training and finding the children eating from buckets of Kentucky Fried Chicken (supplied by the director). But now that the director has changed, the chances of implementing the program are much higher. Schools in areas with high SES may snub the opportunity to take up financial incentives to improve their practices. By contrast in rural areas with low SES, the programs are taken up more readily because they represent new resources and opportunities.

Some teams see it as their priority to get all schools on board, as expressed in the following quote from a conversation with a practitioner:

Kelly says that ... schools in other areas "out near X" that are having more trouble, for example: they have many more students, communication problems between students who speak different languages. These are schools that she wants to spend more time with.

And from the same team:

Pat says that the schools that are performing well are engaged, and asking for more resources than the health promotion practitioner is able to provide. Whereas the schools that need support don't come to the teleconferences that the LHD hosts to support them, so it's harder to interact with them

One LHD had an explicit equity-tool to help them classify schools most at risk and assist them to target their practice towards helping them. This helps them think through how they are assigned sites to staff, allowing them to weight services with lower KPIs so that staff don't have too many in their workload. 
To us the practices described through the quotes presented in this last batch, speak of equity as a common value, and we have named them equity driven practice.

\section{Summary of results: KPI driven practice, relationship driven practice, and equity driven practice}

In these results, team strategies toward KPIs have been used to interrogate the links between the KPI system and practitioners' approaches to health promotion practice. Overall, we found differences in team strategy towards KPIs. Some teams go "indicator by indicator", that is they plan the agenda of their visits to schools or early childhood services according to the indicator they need to boost (i.e., tackling the same indicator in multiple sites at once). Other teams go "site by site" meaning that they plan the agenda of their visits according to the needs of the school or early childhood service and whatever indicator needs attention. Finally, there are some teams who strive to get all sites to perform well. In these teams their focus is on assisting schools or early childhood services most in need to implement the program (regardless of whether the KPI target for the local area may have been reached).

Likewise, we have found differences in the attitudes that the teams have expressed regarding KPIs; some seem to take pride in performing well, and would make a point of celebrating target achievement. Some say they try not to focus on KPIs. Then there are some teams who are pragmatic about meeting a sufficient number of KPIs, so they can focus on what they consider to be their real priorities.

The approach to KPIs reflected a similar attitude to the HCI programs. Some teams took the obesity prevention practice delivery guide to their site visits and followed it step-by-step. Other teams found that the practices in the guide did not fit the kind of health promotion they believe will get them results in their area, an example of this is areas with a high proportion of non English speaking families where there are cultural or language barriers that need to be addressed. For example one practitioner told the story of going to speak with a school about the obesity prevention program and the principal told her that that day he was dealing with eight displaced students who did not have housing. Teams with low staff turnover and supportive management were able to plan ahead and be strategic about when to introduce obesity prevention practices. Teams with less stable environments struggled to balance priorities and they found it hard to keep up with KPIs. They appeared to be operating with less choice and discretion. While there were differences in how 'loose' the teams interpreted the delivery guide, it is important to note that all teams agreed with the aim of reducing childhood obesity and they all applied their professional skill to support the sites to implement the practices.

Overall, it seemed that three different types of practice could be discerned from how the practitioners approached implementation of HCI and the associated KPIs. We have characterised these approaches as KPI-driven, relationship-driven and equity value-driven. It is important to note that each of these types of 
practice were present in some ways in all LHDs, but we feel that the style of work in certain LHDs tended toward a particular type of practice. See Table 1.

[insert table 1 here]

We also found practitioners to be reflective about the impact of HCI and PHIMS on their daily practice of health promotion. While some practitioners were highly enthusiastic and pleased with the structure provided through PHIMS to assist them in delivering the HCI and meeting targets, one person was wistful about the overall cost of this style of health promotion:

"The problem with HCI for me is that (staff) have gotten into a routine of how they do things. They have a checklist of what they do and they've lost some of the traditional health promotion skills.... If they need to step out and do something around (say) smoking or the Get Healthy Service, they really struggle...

\section{DISCUSSION}

Our three types of practice style are summative generalisations and, in that sense, they are crude depictions of reality. Participants in the study, when provided the opportunity to discuss these results, confirmed that the types were recognisable and resonated well. The value of the typology is that it opens the door to discuss the advantages and disadvantages of each practice style and possibilities for how performance management systems could adjust. In spite of the variety of practice styles KPIs for nutrition and physical activity are largely being met across the state (Lockeridge et al 2015; Bravo et al 2016). One could argue that the variety of practice styles we have observed has not "derailed" the scale up of the programs and in fact likely affords the achievement of local benefits or gains without significant loss of accountability to the Ministry for program implementation.

Our ethnography took place after the e-monitoring system for recording KPIs (i.e., PHIMS) had been in place for 4 years. Our findings may have been different if we had conducted the empirical work at an earlier time period, yet we observed behaviours that are similar to what other researchers investigating performance management systems have found. For example, Pollitt (2013) synthesised research evidence in performance management systems and observed that the simple logic "hit your target and get 
rewarded" is surrounded by number of competing "alternative logics" that take into account broader rationalities and allegiances to what people see as the right way to act. While a performance management system (which we define here as a set of structures set up to improve practice which is not reaching a standard) might not be the same as a performance monitoring system (a recording system with funding agreements attached, like we are studying here), they likely share some characteristics. Pollitt (2013) noted that performance management systems have "rachet effects" where managers are tempted to meet but not exceed last year's targets, in case targets are raised and become harder to achieve. These effects have been observed extensively in the National Health Service in the UK (Goddard et al, 2000) and in other European country ministries (Nakrosis, 2008). We could argue that the quote from T1 where the manager is happy for it to seem like "they are working hard for their money", could be seen as a rachet effect. While some might call this "gaming", Johannsson (2016) has pointed out that what get defined as gaming depends very much of the perspective of the observer, and at the level of "street-level bureaucrats", i.e., professionals who work in human welfare, many such behaviours might be understood as "coping" strategies that enable resources to be put to better use, in their own determination. Certainly, the local health teams focussed on "going beyond KPIs" when targets had possibly already been reached, are exercising a logic that is outside the immediate domain of the KPIs' ostensive purpose. This behaviour is the opposite of what would be considered choosing the "low hanging fruit". On the other hand, we did see behaviour that we termed "strategic", that is, visiting just enough of schools that were borderline, in terms of adopting an indicator, in order to nudge them over the edge and achieve a team target. Doing just enough to achieve a target ostensibly ticks all the boxes and might be considered success, yet in other ways it might be considered a "perverse effect" (Shore and Wright, 2015) if the most difficult schools or early childcare services are always in the $10-20 \%$ that are not reached by evidencebased programs.

It is vital that ethnographies such as ours are not seen merely as opportunities to gain insights for design of better centrally- controlled systems. In the presence of complexity, better controlled systems are illusory. Instead, we can strive towards better, faster, mutual adaptation and adjustment of co-existing state wide and local systems, where working together to achieve state wide goals does not erode local teams' capacity to address issues for which there is local level accountability

The implementation of the HCI might therefore be best seen as orchestrating an act of alignment across systems (Hawe et al 2009) rather than the spread of a particular program. When it comes to understanding change processes, this is consistent with a policy implementation research approach rather than a strictly defined implementation science one (Nilsen et al 2013). Indeed the KPIs for the HCI are not about implementing a particular program in a particular way. The KPIs are a set of obesity-preventing practices 
required in schools and early childhood services. The KPIs in our study are destinations, not prescribed pathways.

The "loose" part of the intended "tight-loose-tight" implementation potentially allows for (1) insights into local level accountabilities and goals; (2) different styles of practice to evolve according to local need and decision latitude; (3) larger-level patterns to emerge; and, ultimately, (4) for the performance monitoring system to adjust. In relation to the last two points, for example, strategic and compensatory actions by practitioners (which we have called here, relationship-driven practice and equity-driven practice) suggest that the next phase of the HCI indicator system design could develop ways for tracking and encouraging equity targets as well as the current reach and implementation targets.

Indicators within KPI schemata could also be made more attuned to recording the enablers of the programs - the subtler actions that make programs effective - rather than just the outcomes. In our case, relationship building is a major aspect of everyday action and the social capital that it produces is drawn on by practitioners when it comes to getting action on KPI targets. We are finding that the relationshipbuilding function of implementing the $\mathrm{HCI}$ is so important that many local health teams are designing their own methods to track relationship building to supplement data that they enter into the electronic recoding system (Conte et al 2019). This underscores an observation by Winthereik and colleagues (2007) that monitoring systems do not simply shape and "do things to" practice. They help create the knowledge that is necessary for what the user/actor considers good practice. In their case, the researchers tracked how an electronic patient record system was turned by GPs into a system of good care, rather than being accepted or suffered as an externally imposed imposition (Winthereik et al, 2007). Thus, accountability and autonomy are co-produced (Winthereik et al, 2007).

\section{CONCLUSIONS AND IMPLICATIONS}

We have explored how practitioners creatively and pragmatically engage with the KPI system as a means of working toward what they consider to be important in their health promotion practice. Rather than viewing a KPI system simply as something that shapes practice, we have shown that practitioners approach the KPI system strategically in a variety of ways. These strategies are sometimes informed by structural capabilities and professional values of the team. From a policy perspective, this means that KPIs cannot stand alone. They are part of a broader process and "low performing" teams might need to be appreciated in terms of what are they achieving in a suite of domains, as yet possibly undetected. Such understanding needs dialogue among the respective parties so that privileged insights (from a one-off 
ethnography like this) become part of the ongoing discourse for practice improvement and target achievement. Undesirable behaviours (including rachet affects or gaming) can never be "magically eliminated" but serve to illustrate that people are focussed on multiple goals at once (Pollitt, 2013) although a monitoring system likely is measuring just one. Further investigation is required to determine how performance monitoring systems could be expanded and adapted to encompass a wider understanding of multiple accountabilities and the strategies that practitioners use to achieve diverse goals.

\section{DECLARATIONS}

Ethics approval and consent to participate: Research ethics approval has been granted by the Royal Prince Alfred Hospital Human Research Ethics Committee (X16-0156 \& LNR/16/RPAH/194), and, in addition, by the research governance offices of each of the 15 LHDs.

\section{FUNDING}

This work was supported by the National Health and Medical Research Council of Australia (NHMRC) through its partnership centre grant scheme (Grant ID: GNT9100001). NSW Health, ACT Health, The Commonwealth Department of Health, The Hospitals Contribution Fund of Australia, and HCF Research Foundation have contributed funds to support this work as part of the NHMRC partnership centre grant scheme.

\section{References}

AIHW 2014. Australia's health 2014. Cat. no. AUS 178. Canberra: AIHW.

Bauer M.S., Damschroder L., Hagedorn H., Smith J. and Kilbourne A.M. (2015) An introduction to implementation science for the non-specialist, BMC Psychology, 3(32).

Bisset S., Potvin L. and Daniel M. (2013) The adaptive nature of implementation practice: Case study of a school-based nutrition education intervention, Evaluation and Program Planning, 39,10-18.

Boxenbaum E. and Jonsson S. (2008) Isomorphism, Diffusion and Decoupling in Greenwood R., Oliver, 
C., Suddaby, R., and Sahlin-Andersson, K. (eds.) The Sage handbook of organizational institutionalism, London: Sage, 78-98.

Bravo, A., Innes-Hughes, C., O'Hara, B. J., McGill, B., \& Rissel, C. (2016). Live Life Well @ School: Evidence and Evaluation Summary 2008-2015. Retrieved from North Sydney:

http://www.preventivehealth.net.au/live-life-well--school.html

Bødker S. (2000) Scenarios in user-centred design — setting the stage for reflection and action. Interacting with Computers 13(1), 61-75.

Conte, KP, Shahid, A, Grøn, S, Loblay, V, Green, A, Innes-Hughes, C, Hawe, P (2019). Capturing implementation knowledge: applying focused ethnography to study how implementers generate and manage knowledge in the scale-up of obesity prevention programs. Implementation Science, 14(1), 91

Conte K, Hawe P. (2018) Will e-monitoring of policy and program implementation stifle or enhance practice? How would we know? Frontiers of Public Health. /fpubh.2018.00243

Conte KP, Groen S, Loblay V, Green A, Milat A, Persson L, Innes-Hughes C, Mitchell J, Thackway S, Williams M and Hawe P (2017) Dynamics Behind the Scale Up of Evidence-Based Obesity Prevention:

Protocol for a Multi Site Case Study of an Electronic Implementation Monitoring System in Health Promotion Practice, Implementation Science 12.

Dickens P. (2016) Tight-loose-tight. A complexity approach to innovation. Organizational Development Practitioner, 48(4), 27-31.

DiMaggio P.J. and Powell W. (1991) The Iron Cage Revisited: Institutional Isomorphism and Collective Rationality in Organizational Fields in Powell W.W. and DiMaggio P.J. (eds.) The New Institutionalism in Organizational Analysis, Chicago: The University of Chicago Press, 63-82.

Dodds P., Wyse R., Jones J., Wolfenden L., Lecathelinais C., Williams A., Yoong S.L., Finch M., Nathan N., Gillham K., Wiggers J. (2014), Validity of a measure to assess healthy eating and physical activity policies and practices in Australian childcare services. BMC Public Health, 14, 572

Dunn M.B., Jones C. (2010) Institutional logics and institutional pluralism: the contestataion of care and science logics in medical education, 1967-2005. Adminstrative Science Quarterly. 55(1), 114-149

Evetts J. (2009) New Professionalism and New Public Management: Changes, Continuities and Consequences, Comparative Sociology, 8, 247-266. 
Farrell L., Lloyd B., Matthews R., Bravo A., Wiggers J. and Rissel C. (2014) Applying a performance monitoring framework to increase reach and adoption of children's healthy eating and physical activity programs. Public Health Research \& Practice, 25(1).

Flay, B.R. (1986) Efficacy and effectiveness trials (and other phases of research) in the development of health promotion programs. Preventive Medicine, 15, 451-474.

Fortun K. (2009) Scaling and Visualizing Multi-sited Ethnography, In: Falzon M (Ed.). Multi-Sited Ethnography, Taylor and Francis.

Fu Y.C.A,, To K.C., Tao W.Y., Kwan K.M.A., Lee Y.H., Fung Y.K.A., Ching C.T.R., Chung W.H.T. (2018). School accreditation scehme reduces childhood obesity in Hong Kong, Global Health Promotion, 29

Goddard M., Mannion R. and Smith P. (2000) The performance framework: taking account of economic behaviour. In: Smith P. (ed.), Reforming Markets in Health Care. Buckingham: Open University Press, $138-61$.

Green A, Innes-Hughes C, Rissel C, Mitchell J, Milat A, Williams M, et al. (2018) Codesign of the Population Health Information Management System to measure reach and practice change of childhood obesity programs. Public Health Res Pract. 28(3)

Hardy L.L., King L., Kelly B., Farrell L. and Howlett S. (2010) Munch and Move: Evaluation of a preschool healthy eating and movement skill program. International Journal of Behavioral Nutrition and Physical Activity, 7:80.

Hawe P., Shiell A. and Riley T. (2009) Theorising Interventions as Events in Systems, Am J Community Psychol, 43, 267-276.

Hawe P., King L., Noort M., Gifford S. and Lloyd B. (1998) Working Invisibly: Health Workers Talk About Capacity-Building in Health Promotion, Health Promotion International, 13(4), 285-295.

Health Information and Quality Authority (2013) Guidance on Developing Key Performance Indicators and Minimum Data Sets to Monitor Healthcare Quality, Dublin: Health Information and Quality Authority.

Hsieh H.F. and Shannon S.E. (2005) Three approaches to qualitative content analysis, Qualitative Health Research, 15(9), $1277-1288$.

Hubbard, L. A., \& Ottoson, J. M. (1997). When a bottom-up innovation meets itself as a top down policy. Science Communication, 19, 41-55 
Innes-Hughes C, Rissel C, Thomas M, Wolfenden L. Reflections on the NSW Healthy Children Initiative: a comprehensive, state-delivered childhood obesity prevention initiative. Public Health Res Pract. 2019;29(1)

Innes-Hughes C, Bravo A, Buffett K, Henderson L, Lockeridge A, Pimenta, N, Radvan D, Rissel C (2017) NSW Healthy Children Initiative: The first five years July 2011 - June 2016. NSW Ministry of Health. https://www.health.nsw.gov.au/heal/Publications/HCI-report.pdf

Kouzes JM, Mico PR. Domain Theory: an introduction to oganizational behavior in human service organizations. Journal of Applied Behavioural Science 1979;15(4):449-469

Lockeridge, A., Innes-Hughes, C., O'Hara, B. J., McGill, B., \& Rissel, C. (2015). Munch and Move: Evidence and evaluation summary. Retrieved from North Sydney:

http://www.preventivehealth.net.au/munch--move.html

Marcus G.E. (1995), Ethnography in/of the World System: The Emergence of Multi-Sited Ethnography, Annu. Rev. Anthropol, 24, 95-117

May C., Johnson M. and Finch T. (2015) Implementation, context and complexity. Implement Sci 2016, 11(1).

Maycock, B., \& Hall, S. E. (2003). The quality management and health promotion practice nexus Promotion \& Education, 10, 58-63.

Merry S.E. (2016) The Seductions of Quantification: Measuring human rights, gender violence, and sex trafficking, University of Chicago Press

Merry S.E. (2011) Measuring the World Indicators, Human Rights and Global Governance, Current Anthropology, 52(3), 83-95

Miller RL, Shinn M. 2005. Learning from communities: overcoming difficulties in dissemination of prevention and promotion efforts. American Journal of Community Psychology 35 (3/4): 169-183

Nakrosis V. (2008) Reforming performance management in Lithuania: towards results-based government. In: Peters G.B. (ed.), Mixes, Matches and Mistakes: New Public Management in Russia and the Former Soviet Republics, Budapest: OGI/LGI, 53-108.

New South Wales Ministry of Health. Service Agreement Template. Sydney: New South Wales Ministry of Health; 2016.

Nilsen, P., Ståhl, C., Roback, K., \& Cairney, P. (2013). Never the twain shall meet?-a comparison of 
implementation science and policy implementation research. Implementation Science, 8(1), 63.

Plsek P.E. and Wilson T. (2001) Complexity, leadership, and management in healthcare organisations. BMJ, 323(7315), 746-9.

Pollit C. (2013) The logics of performance measurement, Evaluation 19(4), 346-363.

Power M. (1999), The Audit Society: Rituals of Verification, PRINTED FROM OXFORD

SCHOLARSHIP ONLINE (www.oxfordscholarship.com).

Saldana J. (2012) The coding manual for qualitative researchers. Thousand Oaks, CA: Sage Publications.

Shore C. \& Wright S. (2015) Audit Culture Revisited, Rankings, Ratings, and the Reassembling of Society, Current Anthropology, 56(3).

Spradley J.(1979) The ethnographic interview. New York: Harcourt Brace Jovanovich.

Scott R.W., Ruef M., Mendel P. and Caronna C.A. (2000) Institutional Change and Healthcare

Organizations: From Professional Dominance to Managed Care. Chicago and London: The University of Chicago Press.

Strathern, M. (2000). Audit cultures: Anthropological studies in accountability, ethics, and the academy. London;New York;: Routledge.

The commission on ending childhood obesity (2016), Report of the commission on ending childhood obesity, World Health Organisation 2016, https://www.who.int/end-childhood-obesity/publications/echoreport/en/

Turpin R.S., Darcy L.R., Koss R., McMahill C., Meynet K., Morton D., Rodriguez J., Schmaltzii S., Schyve P., and Smith P. (1996) A Model to Assess the Usefulness of Performance Indicators, International Journal for Quality in Health Care, 8(4), 321-329.

Varkey P, Reller MK, Resar RK. (2007) Basics of quality improvement in health care. Mayo Clin Proc. $82: 735$

Wiggers J., Wolfenden L., Campbell E., Gillham K., Bell C., Sutherland R., Hardy L.L., King L., Grunseit A., Milat A.J. and Orr N. (2013) Good for Kids, Good for Life, 2006-2016: Evaluation Report. NSW Ministry of Health.

Winthereik B.R., van der Ploeg, I. and Berg M. (2007) The Electronic Patient Record as a Meaningful Audit Tool - Accountability and Autonomy in General Practitioner Work, Science, Technology, \& Human Values, 32(1) 6-25. 
Wutzke S, Redman S, Bauman A, Hawe P, Shiell A, Thackway S, Wilson A. (2017) A new model of collaborative research: experiences from one of Australia's NHMRC Partnership Centres for Better Health. Public Health Research and Practice 27(1)

Figure 1 The organisational support for program delivery and KPI monitoring

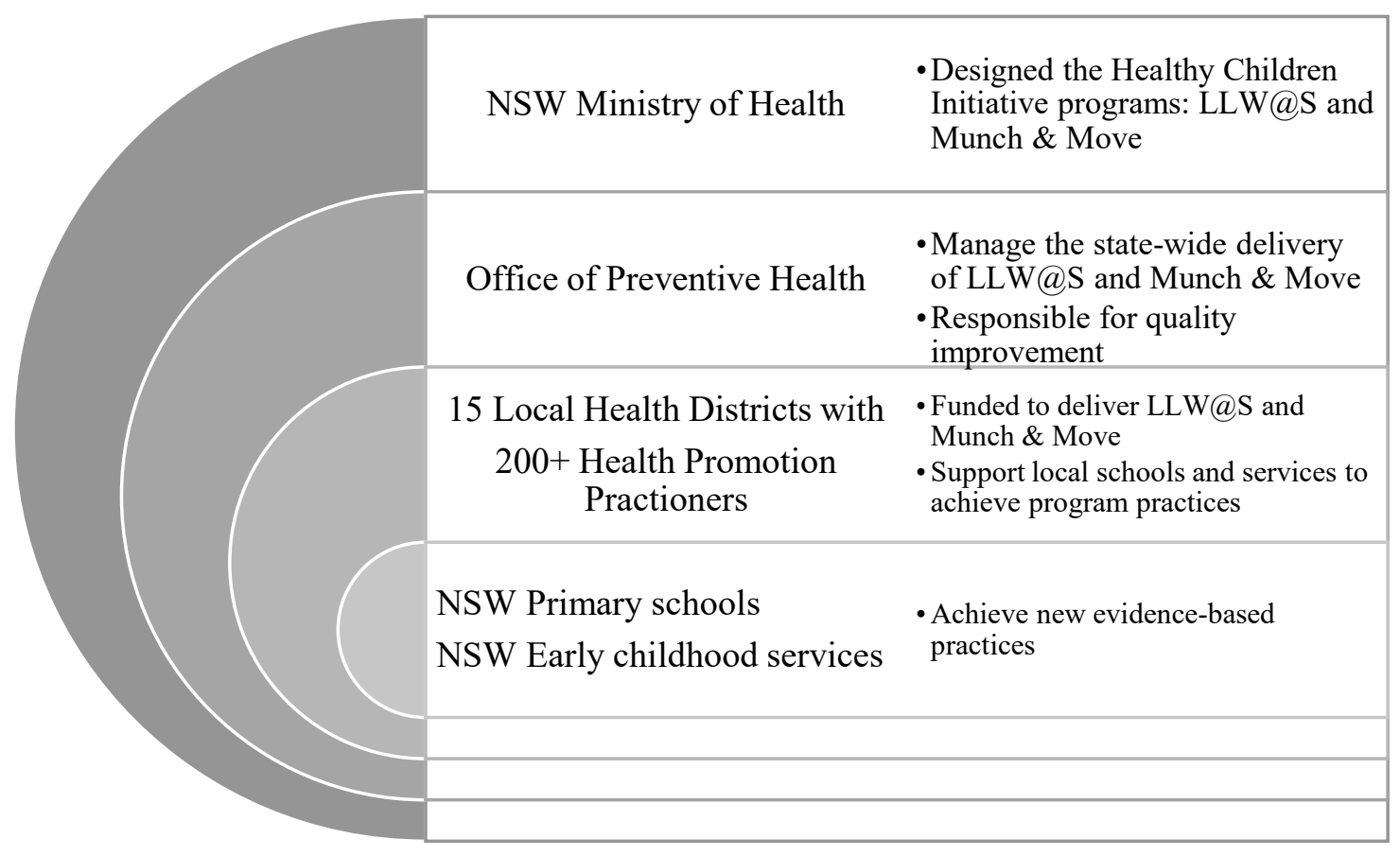

\section{Box 1 Illustrative KPI indicators}

\begin{tabular}{|l|l|}
\hline $\begin{array}{l}\text { Live Life Well @ School (LLW@S) (in } \\
\text { primary schools) }\end{array}$ & $\begin{array}{l}\text { Munch \& Move (M\&M) (in early childhood } \\
\text { services) }\end{array}$ \\
\hline $\begin{array}{l}\text { The school provides curriculum learning } \\
\text { experiences regarding healthy eating, physical } \\
\text { activity and sedentary behaviour. }\end{array}$ & $\begin{array}{l}\text { Site monitors food and drinks that are in } \\
\text { children's lunchboxes each day }\end{array}$ \\
\hline $\begin{array}{l}\text { The school explicitly addresses fundamental } \\
\text { movement skill development as part of the } \\
\text { PDHPE programs. }\end{array}$ & $\begin{array}{l}\text { Site menu includes fruit and vegetables at least } \\
\text { once per day. }\end{array}$ \\
\hline $\begin{array}{l}\text { The school provides the opportunity for classes to } \\
\text { eat vegetable and fruit and drink water. }\end{array}$ & $\begin{array}{l}\text { Physical activity for at least 25\% of opening hours } \\
\text { (ages 1-5 years) }\end{array}$ \\
\hline
\end{tabular}


Table 1: Teams' attitudes in three areas to indicate type of practice style associated with KPI monitoring

\begin{tabular}{|c|c|c|c|}
\hline & Teams $^{1}$ & Teams & Teams \\
\hline \multirow[t]{6}{*}{$\begin{array}{l}\text { Implementation } \\
\text { strategy }\end{array}$} & Focus on KPIs & $\begin{array}{l}\text { Focus on the sites' } \\
\text { progress }\end{array}$ & Focus on reach \\
\hline & T4 & T11 & T9 \\
\hline & T12 & $T 2$ & T10 \\
\hline & T13 & $T 1$ & $T 7$ \\
\hline & T3 & T5 & \\
\hline & T8 & T6 & \\
\hline \multirow[t]{7}{*}{ Attitude to KPI } & Competitive & $\begin{array}{l}\text { KPIs are a hurdle to } \\
\text { accomplish to have } \\
\text { space to work on self- } \\
\text { identified priorities }\end{array}$ & $\begin{array}{l}\text { Try not to let KPIs } \\
\text { distract them }\end{array}$ \\
\hline & T4 & $T 2$ & T9 \\
\hline & T12 & T3 & T10 \\
\hline & T11 & $T 1$ & $T 7$ \\
\hline & & T8 & T5 \\
\hline & & $T 13$ & \\
\hline & & T6 & \\
\hline \multirow[t]{6}{*}{ Attitude to programs } & $\begin{array}{l}\text { Cooperative with } \mathrm{HCl} \\
\text { intention, compliant } \\
\text { with } \mathrm{HCl} \\
\text { implementation } \\
\text { instructions and guides }\end{array}$ & $\begin{array}{l}\text { Strategic -the need to } \\
\text { meet KPIs are an } \\
\text { opportunity to see how } \\
\text { local goals and } \\
\text { priorities and } \mathrm{HCl} \\
\text { requirements can be } \\
\text { aligned }\end{array}$ & $\begin{array}{l}\text { Pragmatically focused } \\
\text { on the immediate } \\
\text { concerns of the local } \\
\text { area }\end{array}$ \\
\hline & T4 & T3 & T9 \\
\hline & T12 & T5 & T10 \\
\hline & T13 & $T 1$ & $T 7$ \\
\hline & T11 & T2 & T8 \\
\hline & & & T6 \\
\hline
\end{tabular}

\begin{tabular}{|llll|}
\hline Overall practice type & & \\
\hline & KPI-driven & Relationships-driven & Equity value-driven \\
& & \\
\hline T4 & T2 & T9 \\
T12 & T5 & T10 \\
T13 & T3 & \\
T11 & T1 & \\
T8 & T6 & \\
\hline
\end{tabular}

\footnotetext{
${ }^{1}$ There are 15 LHDs and 14 teams as one team serves two LHDs. One team was excluded from the typology, which leaves 13 teams.
} 
